\title{
A TENDÊNCIA HISTÓRICO-CRÍTICA: OS DESAFIOS DA EDUCAÇÃO SUPERIOR PARA A PRODUÇÃO INTELECTUAL E EMANCIPAÇÃO
}

\author{
Andréa Kochhann ${ }^{1}$ \\ Douglas Correia dos Santos ${ }^{2}$ \\ Natalia Ribeiro Teixeira ${ }^{3}$
}

\section{INTRODUÇÃO}

Esse trabalho reflete discussões do GEFOPI - Grupo de Estudos em Formação de Professores e Interdisciplinaridade, de projetos de pesquisa, extensão e doutorado, tendo como objeto a tendência histórico-crítica. Na Universidade, centro de excelência da pesquisa, deve-se produzir intelectualmente. Sendo necessárias metodologias possibilitadoras ao acadêmico compreender os conteúdos, gostar da pesquisa e produzir cientificamente.

No presente momento esta temática está sendo abordada por um projeto de pesquisa intitulado "EMANCIPAÇÃO HUMANA: possibilidades e dificuldades de alcance pela práxis acadêmica", que se organiza em cinco subprojetos. Um dos subprojetos é o nosso projeto de investigação, o qual subsidiará a elaboração de nosso trabalho final de curso.

Desta forma buscaremos leituras de Marx (1987) e Gramsci (1995) que afirma que o homem não pode ser alienado ou reificado. Para Marx (1987) é necessário mudar o sistema econômico pela forma como os homens se relacionam com a produção material e intelectual. Para Gramsci (1995) o homem precisa ser emancipado. Essa mudança ocorrerá pela educação emancipadora que gera autonomia, pela tendência histórico-crítica. Portanto, "Como a tendência históricocrítica pode viabilizar a produção intelectual no Ensino Superior e a emancipação?”.

\section{METODOLOGIA}

\footnotetext{
${ }^{1}$ Doutoranda em Educação pela UnB. Dedicação Exclusiva da UEG Câmpus de Jussara e São Luís de Montes Belos. andreakochhann@yahoo.com.br

${ }^{2}$ Pedagogo pela UEG. Pós graduando em Docência Universitária. . douglascorreiadossantos@gmail.com

3 Acadêmica do Curso de Pedagogia UEG- Câmpus de São Luís de Montes Belos.nataliaribeiro7@hotmail.com
} 
Esse trabalho é reflexo de uma pesquisa qualitativa. A metodologia utilizada será a análise bibliográfica com estudos em Marx (1987) sobre a sociedade capitalista e a reificação, Gramsci (1995) sobre as questões educacionais e a emancipação, Meszáros (2008) sobre a educação na sociedade capitalista, Silva (2015) e Saviani (2009) sobre a tendência histórico-crítica e outros.

Valer-se-á da revisão de literatura, em teses e dissertações pela busca no banco de dados da CAPES, do IBICT e das bibliotecas digitais da Pontifícia Universidade Católica de Goiás, da Universidade Federal de Goiás e da Universidade de Brasília. O descritor de busca é "Tendência histórico-crítica".

Realizar-se-á a análise dos resumos e palavras-chave de cada trabalho encontrado. Serão analisados os que apresentam discussão sobre a produção intelectual e emancipação. Mediante as análises criar-se-á categorias de discussão. A intenção é conhecer o que dizem os trabalhos encontrados sobre a produção intelectual e a emancipação.

Após os conceitos formados elaborar-se-á um questionário misto que será testado e quando validado será enviado por email aos coordenadores dos cursos de Pedagogia dos 15 Câmpus da UEG, com o intuito de conhecer o entendimento dos mesmos sobre a tendência histórico-crítica, a produção intelectual e a emancipação. Por fim, uma entrevista semi-estruturada com um estudioso da teoria histórico-crítica.

\section{DISCUSSÃO TEÓRICA}

A tendência histórico-crítica busca a emancipação do homem enquanto um ser crítico, pensante e autônomo. Discutir sobre a formação de professores que a Universidade oferta se torna importante mediante as questões sociais postas atualmente.

A sociedade do conhecimento é uma sociedade pensante e crítica. Inferimos que não somos uma sociedade do conhecimento, mas uma sociedade da informação. Pois, os sujeitos não sabem interpretar, criticar e "pensar". Uma das causas para essa questão é a educação, ou seja, a falta de educação com qualidade. 
É papel da Universidade, em seus cursos de licenciatura, formar os futuros professores, para a produção intelectual, autonomia e a emancipação. Por isso, as metodologias de trabalho pedagógico nos cursos de formação, devem visar a produção intelectual e a emancipação.

A inquietação que gerou essa investigação, faz parte do projeto de pesquisa "EMANCIPAÇÃO HUMANA: possibilidades e dificuldades de alcance pela práxis acadêmica". Contudo, surgiu com base nas considerações de um projeto de pesquisa intitulado "APRENDIZAGEM SIGNIFICATIVA E A FILOSOFIA COMO CONTRIBUIÇÃO PARA A CONSTRUÇÃO DA AUTONOMIA" e de um projeto de extensão registrado como "CONHECENDO A APRENDIZAGEM SIGNIFICATIVA DE DAVID AUSUBEL".

As considerações desses projetos apresentam que a TAS - Teoria da Aprendizagem Significativa viabiliza uma aprendizagem que leva a elaboração científica e possibilita um olhar mais crítico para a realidade. Isso sugere que a TAS pode ser uma metodologia que promova a produção intelectual e a emancipação. Contudo, há divergências entre o posicionamento da TAS enquanto tendência tecnicista ou tendência histórico-crítica.

A Tendência histórica-crítica é fundamentada por Saviani, a partir do método do Materialismo Histórico e Materialismo Dialético de Marx e Engels. O materialismo histórico é o movimento das ideias ao longo da época, pode-se afirmar que

É o materialismo histórico, uma das componentes fundamentais da filosofia marxista-leninista, que elabora a teoria geral e o método de conhecimento da sociedade humana como sistema, estuda as leis da sua evolução e a sua utilização pelos homens. (SPIRKINE; YAKHOT, 1975b, p. 10, grifos do autor).

O materialismo dialético explica as contradições da história,

Na concepção de Marx, como na de Hegel, a Dialética compreende o que hoje se chama de teoria do conhecimento ou gnoseologia, que deve igualmente considerar seu objeto do ponto de vista histórico, estudando e generalizando a origem e o desenvolvimento do conhecimento, a passagem da ignorância ao conhecimento. (LENIN, 1979, p.20) 
Neste sentido, as contradições fundamentadas na materialidade da história, em que os homens são condicionados a viver, produzir e reproduzir ideologias perpetuadas pela classe dominante. Assim, os instrumentos de produção estão nas mãos da classe que representa a força material e sucessivamente também domina a força material.

Na lógica deste discurso, a fundamentação de uma educação que na sua funcionalidade seja capaz de romper com a lógica coerciva do capital é necessário, primeiramente, que a classe subalterna da sociedade, tenha consciência dos efeitos e não somente das causas imbricadas na totalidade do sistema capitalista.

A ambivalência entre a tendência histórica crítica e tecnicista, apresenta suas contradições nos aspectos de formação dos sujeitos, enquanto uma busca por meio do contexto histórico construir cidadãos críticos na outra prevalece a técnica para inserção da mão de obra para trabalho. Pois na concepção de Marx (1998, pp.41-42)

[...] enquanto o trabalho em máquinas agride o sistema nervoso ao máximo, ele reprime o jogo polivalente dos músculos e confisca toda a livre atividade corpórea e espiritual. Mesmo a facilitação do trabalho torna-se um meio de tortura, já que a máquina não livra o trabalhador do trabalho, mas seu trabalho de conteúdo. Toda produção capitalista, à medida que ela não é apenas processo de trabalho, mas ao mesmo tempo processo de valorização do capital, tem em comum o fato de que não é o trabalhador quem usa as condições de trabalho, mas, que, pelo contrário, são as condições de trabalho que usam o trabalhador [...] a habilidade pormenorizada do operador de máquina individual, esvaziado, desaparece como algo íntimo e secundário perante a ciência, perante as enormes forças da natureza e do trabalho social em massa que estão corporificadas no sistema de máquinas e constituem com ele o poder do patrão [...] $A$ maquinaria do patrão desempenha, de fato, um papel muito mais importante no negócio da produção do que o trabalho e a habilidade do operário, que se adestra com um treino de 6 meses e que qualquer peão de campo pode aprender.

O conhecimento construído na Universidade está sujeito às transformações que emergem na estrutura da sociedade. Desta forma, o professor como mediador e orientador, vai criar possibilidades para que o aluno compreenda os conceitos e produza intelectualmente. Pessoas pensantes, críticas e produtoras de conhecimento podem se tornar emancipadas e não alienadas. Silva (2011, p. 22) assevera que "A concepção de formação de professores na perspectiva críticaemancipadora busca construir a indissociabilidade de teoria e prática na práxis". 
Na concepção de Saviani (2003) a pedagogia Histórico-Crítica volta-se para a formação social e transformação do pensamento, se apoiando na crítica alicerçada na historicidade, visando a emancipação. Para o autor existe 5 passos inerentes as estratégias do trabalho pedagógico que o professor deve levar em consideração durante suas aulas. O primeiro é a prática social inicial. O segundo é a problematização. O terceiro é a instrumentalização. O quarto é a catarse. $O$ quinto é a prática social final.

A primeira fase consiste em que o professor deve ter um ponto de partida de todo o trabalho, ou seja a prática se inicia quando o professor realiza uma interação com seus alunos, utilizando assim dos conhecimentos prévios sobre o conteúdo.

A segunda fase é da problematização que se caracteriza entre o elo entre a Prática Social e a Instrumentalização. É a "identificação dos principais problemas postos pela prática social. [...]. Trata-se de detectar que questões precisam ser resolvidas no âmbito da Prática Social e, em consequência, que conhecimento é necessário dominar" (Saviani, 1991, p. 80). A finalidade da problematização é junto com os alunos entender as principais questões relacionadas ao cotidiano, levando para a parte teórica do conteúdo.

A terceira fase segundo Saviani (1991, p. 103) consiste na apreensão [...] dos instrumentos teóricos e práticos necessários ao equacionamento dos problemas detectados na prática social. [...].que a práxis do professor deve ir de encontro com o aluno, na sua constituição social, para que as mudanças acontecem dentro da escola na construção da consciência do aluno não seja algo, todavia, no abstrato, mas concreta na concepção de contradição da realidade.

A quarta fase, é caracterizada pela Catarse que Segundo Saviani (1991, p. 80-81), [...] catarse é a expressão elaborada da nova forma de entendimento da prática social a que se ascendeu. [...]. Seria o momento em que o aluno demonstra que está entendendo o assunto que está sendo discutido. Fase que o aluno assimila os conteúdos trabalhados com os que foram realizados anteriormente. $\grave{E}$ um momento considerado muito importante no processo educacional levando em conta a passagem da síncrese à síntese.

A quinta fase, conforme afirma Savianni a prática Social, que é a mesma prática social inicial, embora com algumas diferenças, pois o alvo a ser atingindo, o problema a ser solucionado, e a prática a ser realizada é a mesma. Para, a 
efetivação dessa tarefa será realizada com mais nitidez e conhecimento. Segundo Saviani (1991, 65 p.82), "[...] o modo de nos situarmos em seu interior se alterou qualitativamente pela mediação da ação pedagógica".

Para isso é necessário que aluno já conheçam o que será estudado tendo uma compreensão melhor do conteúdo, aqui se apresenta a dualidade da ação da pratica, por meio de ação fomentada no contexto teórico e pratico, junto ao contexto social. Em outras vertentes a tendência histórico-crítica tem como objetivo a produção do conhecimento critica, como melhor ferramenta para tornar o aluno emancipado novamente corroborando com Dozol (1994, p 107)

a concepção histórico-crítica define a escola enquanto uma agência socializadora do saber sistematizado, produzido e acumulado historicamente pela humanidade, entendido como uma ferramenta cultural a ser utilizada pelos sujeitos em função dos seus interesses de classe no processo de transformação social.

A formação dos homens se projeta em um paralelo entre a formação crítica e as personificações do sistema capitalista que visa o lucro. Constituir trabalhadores pensantes é uma necessidade emergente no mercado, porém, a contradição que os sujeitos são pensantes, mas não emancipados. Perante essas considerações elaborou-se o problema dessa investigação.

Pensar exige tempo e disposição, algo que somente é particular dos seres humanos. Sendo até mesmo, uma questão de distinção entre eles. Todo ser é pensante, porém segundo Gramsci (1995) o trabalho intelectual distingue os homens na produção material. A produção constitui o desenvolvimento social, construído pelo próprio animal social, pela sua capacidade racional de produção tanto coletiva ou individual.

A produção intelectual hoje tem $O$ desafio da qualidade. $E$ as universidades, principalmente as públicas, têm o dever de possibilitar uma formação para a produção intelectual e a emancipação. Para Saviani (2008) a educação tem a premissa de valorização da humanidade e da formação para a emancipação.

\section{CONSIDERAÇÕES}

Os últimos projetos de pesquisas e de extensão realizados pelos 
componentes do GEFOPI suscitaram o questionamento sobre a tendência históricocrítica e os desafios da educação superior para a produção intelectual e emancipação. Essa pesquisa está em fase embrionária, da discussão bibliográfica e da coleta de dados dos trabalhos.

A Universidade Estadual de Goiás, enquanto uma instituição pública, multicampi e interiorizada, que se encontra espalhada por 39 cidades do Estado, representa que os cursos de licenciatura da UEG formam muitos professores do Estado de Goiás. Nesse ínterim discutir sobre tendências educacionais, a produção intelectual, autonomia e emancipação se fazem necessário. A formação de professores críticos e emancipados, que saibam produzir intelectualmente deve ser a missão das universidades públicas.

\section{REFERÊNCIAS}

DOZOL Marlene de Souza. Concepção histórico-crítica da educação: duas leituras. Publicado na Revista da ANDE, n. 11, 1986. https://periodicos.ufsc.br/index.php/perspectiva/article/viewFile/10818/10298

GRAMSCI, A. Cadernos do cárcere. Edição e tradução: Carlos Nelson Coutinho. Rio de Janeiro: Civilização Brasileira, 2000.

GRAMSCI, A.Concepção dialética da história. Tradução de Carlos Nelson Coutinho. 10. ed. Rio de Janeiro: Ed. Civilização Brasileira, 1995.

GRAMSCI, A. Caderno 12 - Documento Especial In: História \& Perspectivas n.5. Uberlândia, 1991.

GRAMSCI, A. Os intectuais e a organização da cultura. RJ: Civilização Brasileira, 1979.

MARX, Karl (1998). O Capital. São Paulo, Nova Cultural, vol. II.

MARX, K. Manuscritos econômicos e filosóficos. Coleção Os pensadores. São Paulo: Nova Cultura, 1987.

MARX, K. Sobre a questão judaica. São Paulo: Boitempo, 2010.In: $\underline{0}$

MARX, K. Salário, preço e lucro. Trad. Paulo Ferreira Leite. 4 ed. São Paulo: Centauro, 2002. 
MARX, K. O capital: crítica da economia política. Rio de Janeiro: Bertand Brasil, 1979.

MARX, K e ENGELS, F. A ideologia alemã: teses sobre Feurbach. São Paulo: Moraes, 1984.

MARX, K. e ENGELS, F. Manifesto do partido comunista. São Paulo: Cortez, 1998.

MÉSZÁROS, István. A educação para além do capital. 2.ed. São Paulo: Boitempo, 2008.

MONASTA, Atílio. Antonio Gramsci ..Tradução: Paolo Nosella. Recife:

Fundação Joaquim Nabuco, Massangana, 2010.

MOREIRA, M.A. Aprendizagem significativa: a teoria e textos complementares. São Paulo, Livraria Editora da Física, 2010.

NAGEL, Lízia Helena. A sociedade do conhecimento no conhecimento dos educadores. Texto aprovado e publicado nos Anais (em CD-ROM) do I Seminário Internacional de Educação. Cianorte: 2001. [Arquivo: SOCIEDconhecim]

RODRIGUES, Alberto Tosi. Sociologia da Educação. 6.ed. Rio de Janeiro: Lamparina, 2007.

SAVIANI, D. Formação de professores: aspectos históricos e teóricos do problema no contexto brasileiro. Revista brasileira de educação.Vol. 14. N.40 Jan/Abril. 2009. In: http://www.scielo.br/pdf/rbedu/v14n40/v14n40a12.pdf

SAVIANI. D. SISTEMA NACIONAL DE EDUCAÇÃO: o lugar da educação superior. educAtiva, Goiânia, v. 13, n. 1, p. 45-66, jan;jun. 2010http://seer.ucg.br/index.php/educativa

SAVIANI, D. Educação socialista, pedagogia histórico-crítica e os desafios da sociedade de classes. In: LOMBARDI, José Claudinei e SAVIANI, Demerval (orgs.). 2. ed.MARXISMO E EDUCAÇÃO: debates contemporâneos. Campinas: São Paulo: Autores Associados, 2008b.

SAVIANI, D. PEDAGOGIA HISTÓRICO-CRÍTICA: primeiras aproximações. 10 ed. Campinas: Autores Associados, 2003.

SILVA, K.A.C.P.C.A FORMAÇÃO DE PROFESSORES NA PERSPECTIVA CRítICO-EMANCIPADORA. Linhas Críticas, Brasília, DF, v. 17, n. 32, p. 13-31, jan./abr. 2011.

SPIRKINE, A. YAKHOT, O. Princípios do Materialismo Dialético. S. São Paulo: Estampa, 1975a. 


\section{APOIO FINANCEIRO}

Agradecemos a UEG pelo apoio financeiro com a bolsa de iniciação científica e

bolsa de extensão. Agradecemos também pelo apoio a eventos, pelo Edital PróEventos. 